Original Research Paper

\title{
Effect of Diurnal Variation of Dissolved Oxygen in a Eutrophic Polymictic Reservoir
}

\author{
Anusha Balangoda \\ Environmental and Conservation Sciences, North Dakota State University, Fargo, ND 58105, USA
}

Article history

Received: 02-11-2016

Revised: 09-01-2017

Accepted: 23-01-2017

Email: Anusha.Balangoda@gmail.com

\begin{abstract}
To evaluate the diurnal and seasonal Dissolved Oxygen (DO) variations and their effects on water quality, a comprehensive study was conducted in a eutrophic polymictic reservoir under artificially aerated and non-aerated conditions. The effect of aeration among sampling locations and along the water column of DO and DO saturation and diurnal variation of $\mathrm{DO}$, water temperature, $\mathrm{pH}$ and conductivity was evaluated under aerated and non-aerated conditions. Dissolved oxygen and water temperature exhibited diurnal variations under aerated and non-aerated conditions; however, no notable diurnal variation was observed in conductivity and $\mathrm{pH}$. The anoxic condition was observed in near-bottom waters at night under non-aerated conditions. The diurnal DO concentration at the surface level was higher under non-aerated conditions than aerated conditions. The diurnal DO variation implies that excessive algae and weed growth cause a major impact on DO production and consumption during the day and night, respectively. The DO concentration at different sampling locations revealed that artificial aeration increased DO concentration in the deep portion of the reservoir. However, results showed that the existing aeration system was inadequate to increase the DO concentration in the entire reservoir.
\end{abstract}

Keywords: Aphanizomenon, Hypoxia, Cyanobacterial Blooms, Fish Kills, Harmful Algal Blooms

\section{Introduction}

This paper evaluates diurnal, spatial and temporal variations of Dissolved Oxygen (DO) and their effect on water quality under artificially aerated and non-aerated conditions in a eutrophic polymictic reservoir. Eutrophic conditions are often associated with an increase in algal biomass and frequent hypoxia in aquatic ecosystems indicate eutrophic conditions (Rabalais et al., 2010; Paerl et al., 2011). The proliferation of undesirable phytoplankton in fresh and marine waters presents and ongoing problem to world's aquatic ecosystems (Steffen et al., 2014). Nuisance algal blooms cause DO depletion and hypoxia or anoxia in the aquatic ecosystems (Stewart and Lowe, 2008; Michalak et al., 2013; Zhou et al., 2013). To maintain a healthy aquatic life, the daily minimum DO requirement claimed to be 5 $\mathrm{mg} / \mathrm{L}$ in the water column (NDDoH, 2010); however, amount of DO needed to prevent mortality differs among species and between life stages. For instance, fish eggs and young fish, are more sensitive to low DO than adults
(Eby and Crowder, 2002; Ludsin et al., 2009). Hypoxia (i.e., DO $<2 \mathrm{mg} \mathrm{L}^{-1}$ ) can affect biological communities in the aquatic ecosystem; for instance, prolonged low DO levels can cause fish kills (Rao et al., 2014) and benthic macroinvertebrate kill (Bridgeman et al., 2006).

To increase dissolved oxygen concentration in the hypolimnion and/or to restore the fish habitats in stratified lakes artificial aeration has been applied to many lakes (Beutel and Horn, 1999; Cooke et al. 2005; Singleton and Little, 2006). Supplying oxygen can prevent hypoxia and nutrient release from anoxic sediments. Apart from the direct effects, there are also other important consequences of decreased levels of oxygen in the water column, for instance, reduced DO concentration can affects nutrient releasing mechanisms as it is the case with Fe desorption and microbial decomposition, which directly affects to stimulate algal growth and eventually lead to lake eutrophication (Christophoridis and Fytianos, 2006; Hupfer and Lewandowski, 2008). Certain aeration systems does not 
disturb thermal stratification and can be kept nutrient depleted in the epilimnion; however, artificial aeration (artificial destratification) induces mixing of entire water body and increase oxygen supply from the atmosphere. Studies have shown the use of artificial aeration to increase dissolved oxygen concentration in the water column under different conditions, such as system undersizing (Gächter and Wehrli, 1998), continued high external load (Gächter, 1987), failure to achieve oxic sediment water interface (Gächter, 1987) and high levels of sediment sulfur (Gächter and Muller, 2003). However, diurnal variation of dissolved oxygen concentration under the conditions of aeration and non -aeration is still compelling. Many studies have reported the effects of oxygenation on lake water quality; however, none of them have focused on the synergistic effects of artificial aeration and diurnal variation of DO in the entire body of water.

This study was done at the Heinrich Martin Dam Impoundment (HMDI), located in southeastern North Dakota. It is a eutrophic polymictic impoundment that is classified as a reservoir for warm water fishery (largemouth bass and bluegill fishery). The bluegill population at the HMDI is very strong and bluegill from the HMDI are used for brood stock around the state. The North Dakota Game and Fish Department has installed an aeration system at the HMDI to increase the DO concentration for the long term purpose of reducing the likelihood of fish kill, increasing the abundance of fish, maintaining better conditions for fish growth.

To evaluate the diurnal variations of DO and their effects on water quality, a comprehensive study was conducted in the HMDI under artificially aerated and non-aerated conditions. Until now, no study has monitored out water quality monitoring designed specifically to maximize obtaining information on the impact of intermittent artificial aeration on diurnal and vertical distribution of DO concentrations that are representative of the entire study area, including deep and shallow areas, as well as other critical areas (i.e., inlet and dead areas). Identifying the impacts of aeration on diurnal and seasonal DO concentrations in the overlying water column of the entire reservoir, as well as its subsequent effects on algal growth is essential to study for effective lake restoration and to control algal blooms during summer. Algal growth is highly responsive to diurnal variations; therefore, conducting a $24 \mathrm{~h}$ water quality monitoring would provide a better understanding of diurnal variations of dissolved oxygen, water temperature and $\mathrm{pH}$ in artificially aerated eutrophic lakes along with an understanding of variation is $\mathrm{N}$ and $\mathrm{P}$ concentration variations. In addition, spatial and temporal variations of DO in entire reservoir provide the effectiveness of existing aeration system to improve the DO concentration in entire reservoir during warm summer to avoid fish kills and other results/effects of undesirable water quality issues.

\section{Materials and Methods}

\section{Description of Study Site}

The Heinrich Martin Dam Impoundment (HMDI) is a relatively shallow, polymictic reservoir located in southeastern North Dakota, USA. The HMDI is located in the Northern Glaciated Plains Level 111 ecoregion which is characterized by flat to rolling landscape composed of glacial drift (Wax et al., 2008). The reservoir is managed by the North Dakota Game and Fish Department. The HMDI is a small reservoir with a surface area of 18.8 acres $\left(0.08 \mathrm{~km}^{2}\right)$ and it is used for recreational activities such as boating and fishing. Typically stable thermal stratification develops in June or July and persists through late August or early September in the deeper portion of the impoundment. Artificial destratification (Fig. 1) was used as a restoration method since 2006 with the exception of 2009 and 2011. In 2011 the aeration system was turned off in July and September. Details of the aeration system are provided in Balangoda (2016).

\section{Sampling Plan}

Six sampling sites (A, B, C, D, G and H) were selected in the impoundment based on the effects from the artificial aeration system, depth variability and location (Table 1; Fig. 2). Site A and B are located in a deeper portion of the impoundment and are near the destratification system while Sites C and D are far from the aeration system; Site $\mathrm{G}$ is closer to the inlet and Site $\mathrm{H}$ is located in the dead area. Table 1 contains the GPS coordinates and depth of each sampling location. Water quality monitoring and samples were collected in 2010, 2011 and 2012. In 2010, water quality monitoring and sampling were carried out under the conditions of aeration at sites A, B, C and D on a bi-weekly basis. In 2011, samples were collected on a bi-weekly basis during an aerated period and weekly during the period without aeration at sites $\mathrm{A}, \mathrm{B}, \mathrm{C}$ and $\mathrm{D}$. In 2012, in addition to four sampling locations (A-D), two new locations, sites $\mathrm{G}$ and $\mathrm{H}$, were added to study the impacts of aeration on DO (dissolved oxygen) and nutrient concentration in the water column.

Dissolved oxygen, water temperature and Electrical Conductivity (EC) were monitored at the surface of the water column and at $1 \mathrm{~m}$ depth intervals throughout the water column at six sampling locations using a YSI (YSI Incorporated, Yellow Springs, OH, USA) multisensor sonde. The measurement error for temperature was estimated to be $\pm 0.15^{\circ} \mathrm{C}$; for conductivity it was estimated to be $0.5 \%$ of the measured value and for DO it was estimated to be $\pm 2 \%$ of the reading (ranging from 0 to $20 \mathrm{mg} \mathrm{L}^{-1}$ dissolved oxygen). 


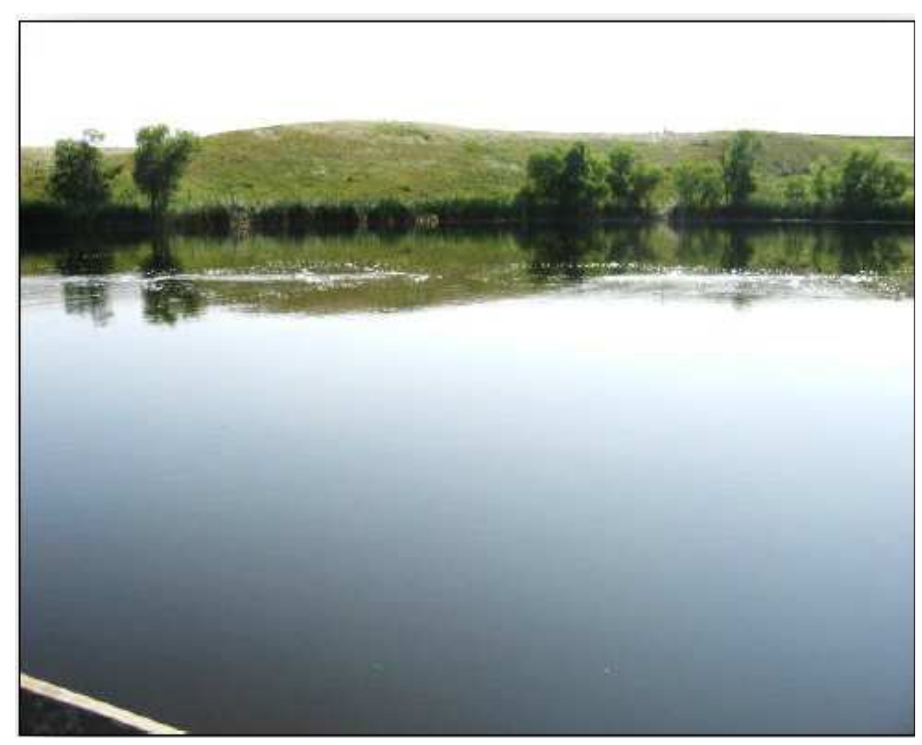

Fig. 1. The HMDI artificial destratification system (Photo by Anusha Balangoda)

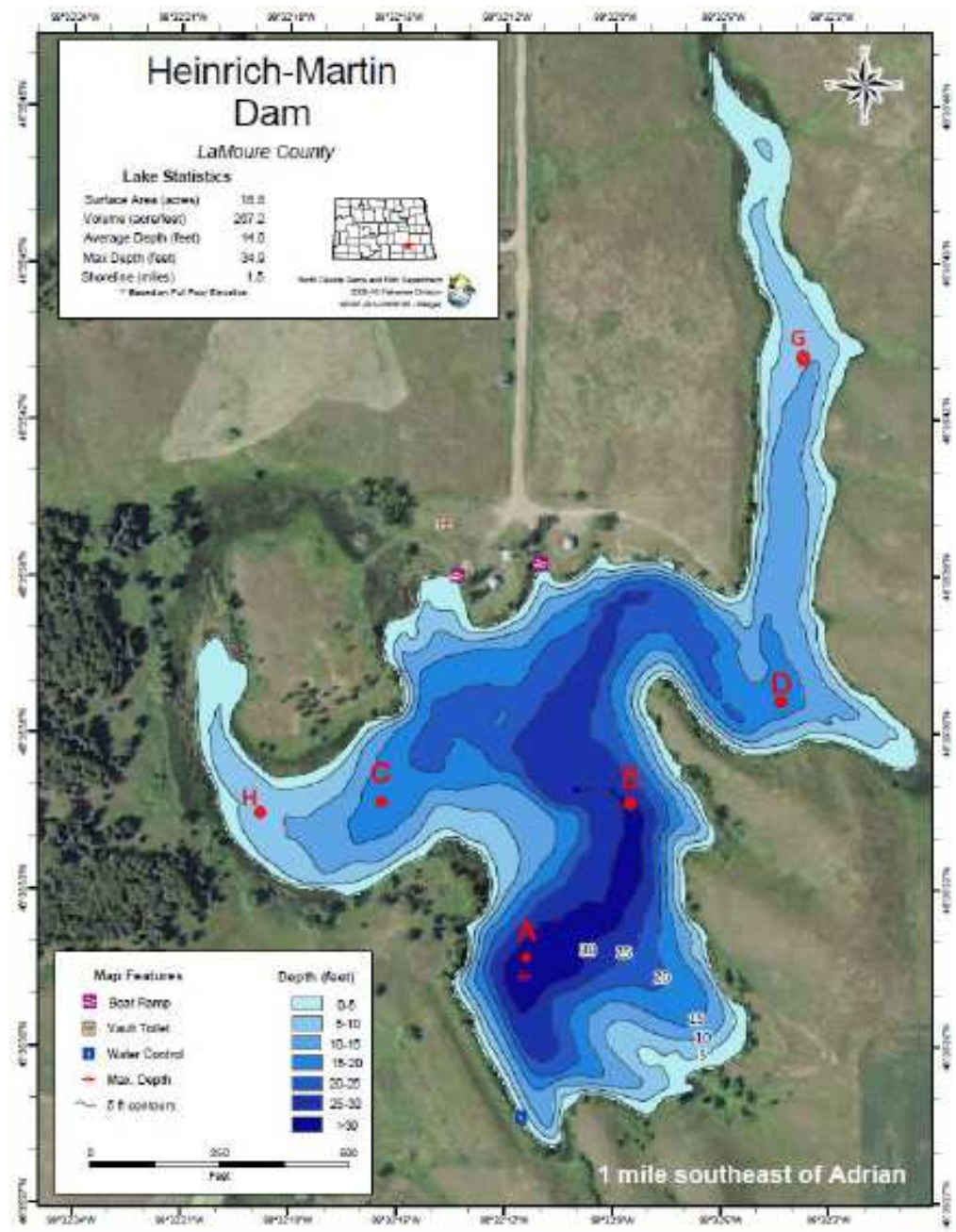

Fig. 2. Map of HMDI showing sampling locations. The inlet is located on the north side, which is in the narrow gully 
Table 1. Depths and GPS coordinates at each sampling locations at the HMDI

\begin{tabular}{lllllrr}
\hline Sampling point & $\mathrm{A}$ & $\mathrm{B}$ & $\mathrm{C}$ & $\mathrm{D}$ & $\mathrm{G}$ & $\mathrm{H}$ \\
\hline Longitude (W) & 98.5362 & 98.5360 & 98.5379 & 98.5347 & 98.5344 & 98.5385 \\
Latitude (N) & 46.5923 & 46.5929 & 46.5930 & 46.5937 & 46.5954 & 46.5930 \\
Water depth(m) & 8.0000 & 6.5000 & 4.0000 & 5.0000 & 1.5000 & 1.5000 \\
\hline
\end{tabular}

\section{Twenty-Four Hour Water Quality Monitoring}

In 2011, a twenty-four-hour water quality monitoring was carried out at non-aerated Site A to study the influence of algal growth on diurnal DO variation in the water column. Dissolved oxygen, DO saturation, conductivity and water temperature were measured at one-meter depth interval in every three-hour interval using a YSI 650 multi-parameter sonde (YSI Incorporated, Yellow Springs, OH, USA). In 2012, a twenty-four-hour water quality monitoring was carried out under the conditions of aeration to compare the influence of algal growth on diurnal DO concentration with non-aerated conditions. Dissolved oxygen, DO saturation, water temperature and conductivity were measured only at the surface water column $(0.5 \mathrm{~m}$ from the surface) due to homogenous mixing using automated YSI 650 multi-parameter sonde.

\section{Results}

\section{Twenty-Four-Hour Water Quality Monitoring}

A 24-hour sampling was carried out to study the effects of algal growth due to nutrient enrichment on diurnal Dissolved Oxygen (DO) variation in the water column during summer months. In addition to $\mathrm{DO}, \mathrm{pH}$, conductivity and water temperature were also measured under aerated and non-aerated conditions; however, only DO and water temperature showed diurnal variations. Dissolved oxygen exhibited diurnal variations due to photosynthesis and respiration of algae, aquatic plants, aquatic animals and microbes. Photosynthesis is the dominant process in determining diurnal variation in eutrophic waters. Figure 3 and 4 show the measured diurnal DO at the HMDI under aerated and non-aerated conditions in 2011 and 2012. In 2011, DO was measured from the surface to the bottom at site A (Fig. 3), while in 2012, diurnal DO and DO saturation were measured only at the surface (Fig. 4). In daylight, due to algal photosynthesis, DO concentration was at its maximum in the afternoon and declined throughout the night due to respiration. The data shows that under non-aerated conditions (lake stratified conditions) the 2011 data shows up to $2 \mathrm{~m}$ of depth, daily minimum DO was above $4 \mathrm{mg} \mathrm{L}^{-1}$ (Fig. 3); however, at the bottom (at $8 \mathrm{~m}$ depth level), diurnal DO was zero throughout the day indicating a greater consumption of $\mathrm{DO}$ for the degradation of organic materials (Fig. 3). In 2012, under aerated conditions, the daily minimum DO concentration at the surface was $3 \mathrm{mg} \mathrm{L}^{-1}$, which was less than the standard DO $\left(5 \mathrm{mg} \mathrm{L}^{-1}\right)$ in the water column (Fig. 4). The DO saturation also exhibited diurnal variations with respect to diurnal DO concentrations in the water column (Fig. 4).

The diurnal cycles of DO concentration and water temperature were inversely related and controlled by the diurnal variations in solar radiation. Comparing Fig. 3-6, it seems clear that diurnal variation of water temperature leads to low DO in the afternoon that photosynthesis leads to high DO in the early morning. Comparing chlorophyll $a$ concentration at the surface of the water column with DO concentrations at the surface of water column shows that increasing of photosynthesis increases $\mathrm{DO}$ in the near surface waters (Balangoda et al., 2015).

\section{Conductivity and $\mathrm{pH}$}

Figure 7 shows that no diurnal variation was observed in conductivity from surface-to-bottom under non-aerated conditions. The conductivity gradient however, was observed along the water column under non-aerated conditions (lake stratified period). The surface layer conductivity remained unchanged at around $775 \mu \mathrm{S} / \mathrm{cm}$ during a $24 \mathrm{~h}$ period however, conductivity increased to around $800 \mu \mathrm{S} / \mathrm{cm}$ at the $3 \mathrm{~m}$ depth level and $865 \mu \mathrm{S} / \mathrm{cm}$ in the bottom layer at the deepest location, site A (Fig. 7). This increase in conductivity in the near-bottom waters indicated that an internal loading of dissolved substances including dissolved inorganic nitrogen, phosphorus and dissolved organic substances derived from microbial degradation and other salts during the period without aeration.

Similar to conductivity, no notable diurnal variation was observed in $\mathrm{pH}$ at the different depths at site $\mathrm{A}$ during the non-aerated period (Fig. 8). Slight differences were observed from surface-to bottom. The $\mathrm{pH}$ at the surface level was remained around 8.75 while it decreased to around 7.5 in the near-bottom water. The diurnal $\mathrm{pH}$ was slightly higher in the afternoon at the surface, $2 \mathrm{~m}$ and $3 \mathrm{~m}$ levels most likely due to carbon dioxide is fixed by algae for photosynthesis during day light hours (Fig. 8). A slightly lower $\mathrm{pH}$ was observed at dawn because of carbon dioxide is produced by decomposition and aerobic respiration. The $\mathrm{pH}$ at the surface of the water column was higher than in the near bottom layers most likely due to carbon dioxide produced by organic matter decomposition. The $\mathrm{pH}$ was maintained within the normal range (6.5-9.0) along the water column throughout a $24 \mathrm{~h}$ period (Fig. 8). 


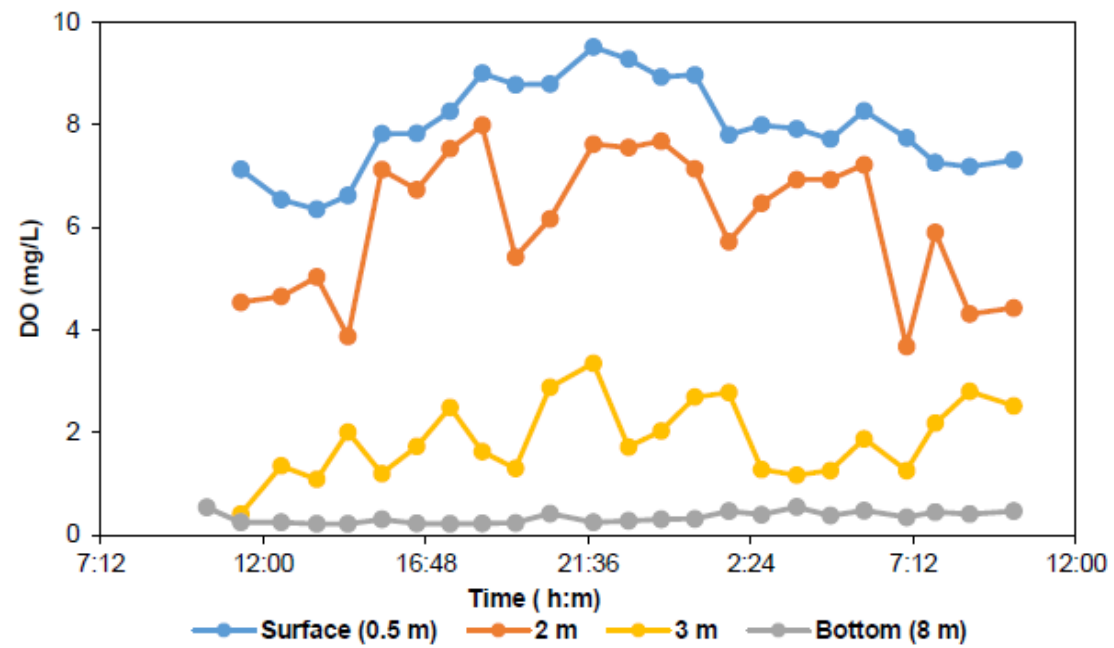

Fig. 3. Diurnal DO variation along the water column under non-aerated (stratified) conditions at Site A (the deepest sampling location)

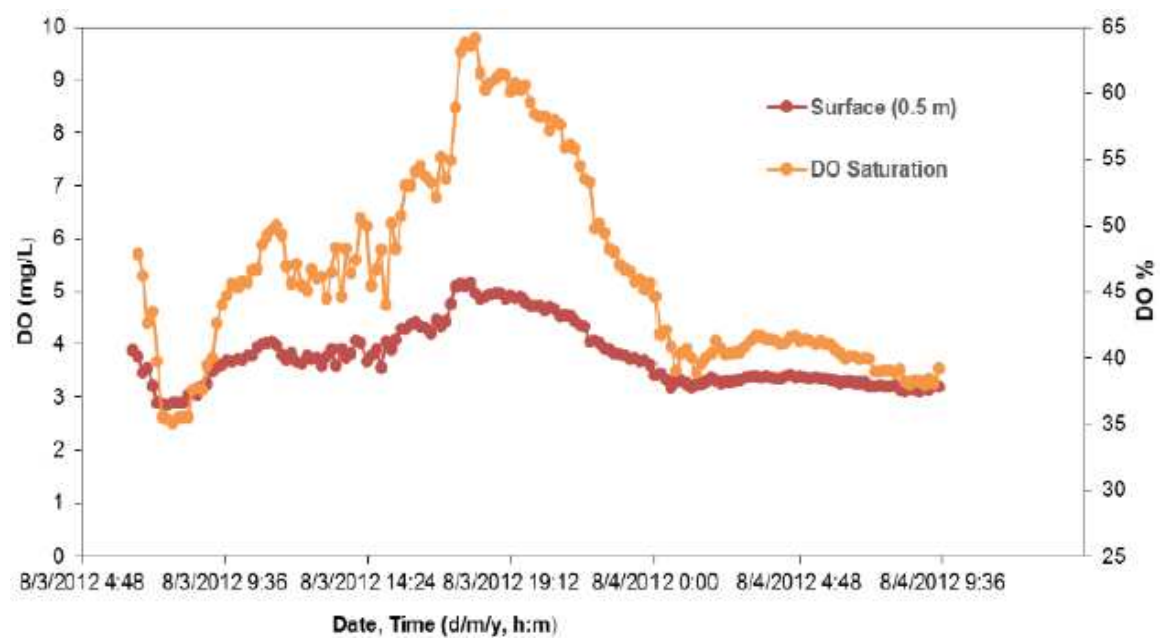

Fig. 4. Diurnal DO variation and DO saturation at the surface under aerated conditions at Site A (the deepest sampling location)

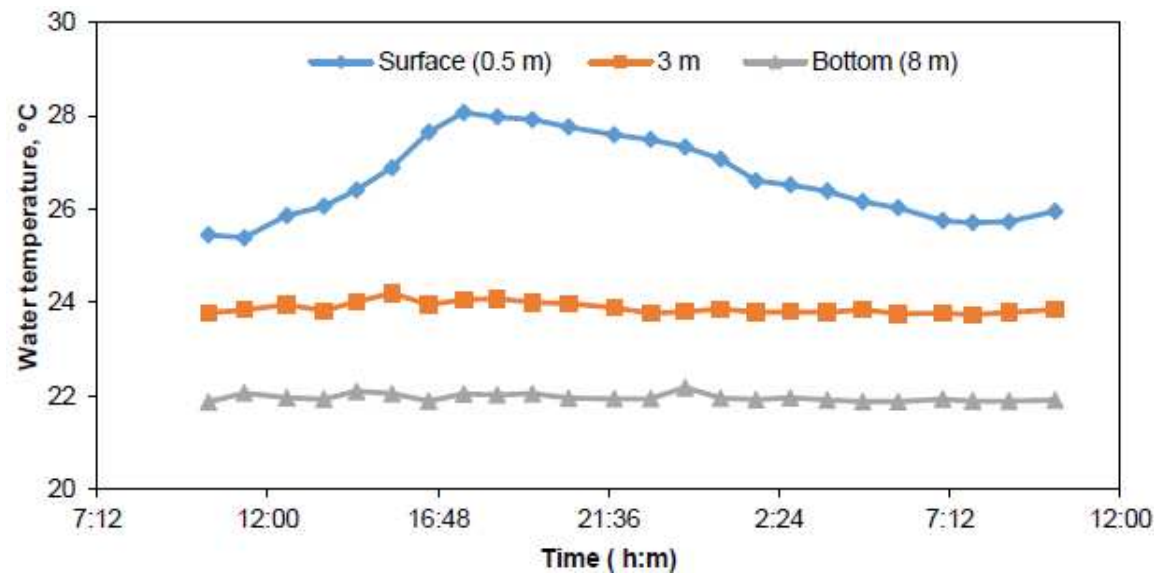

Fig. 5. Diurnal water temperature variation along the water column under non-aerated conditions at Site A (the deepest sampling location) 


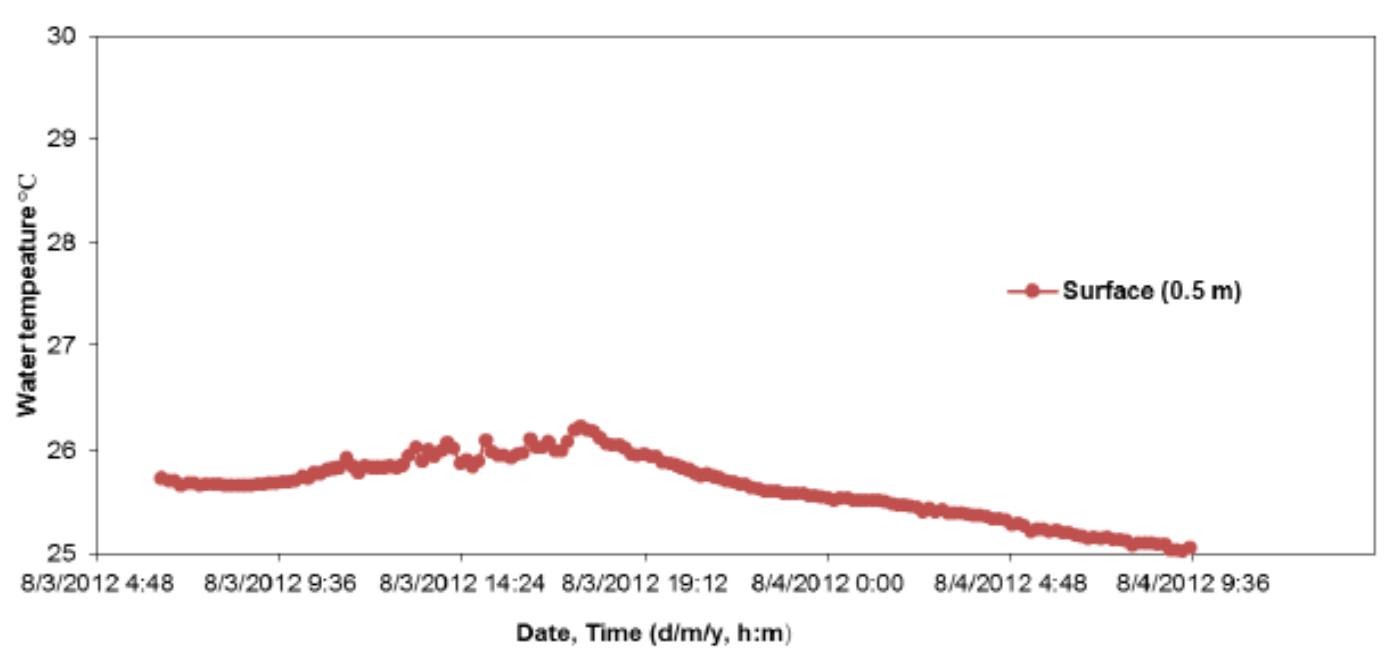

Fig. 6. Diurnal water temperature at the surface under aerated conditions at Site A (the deepest sampling location)

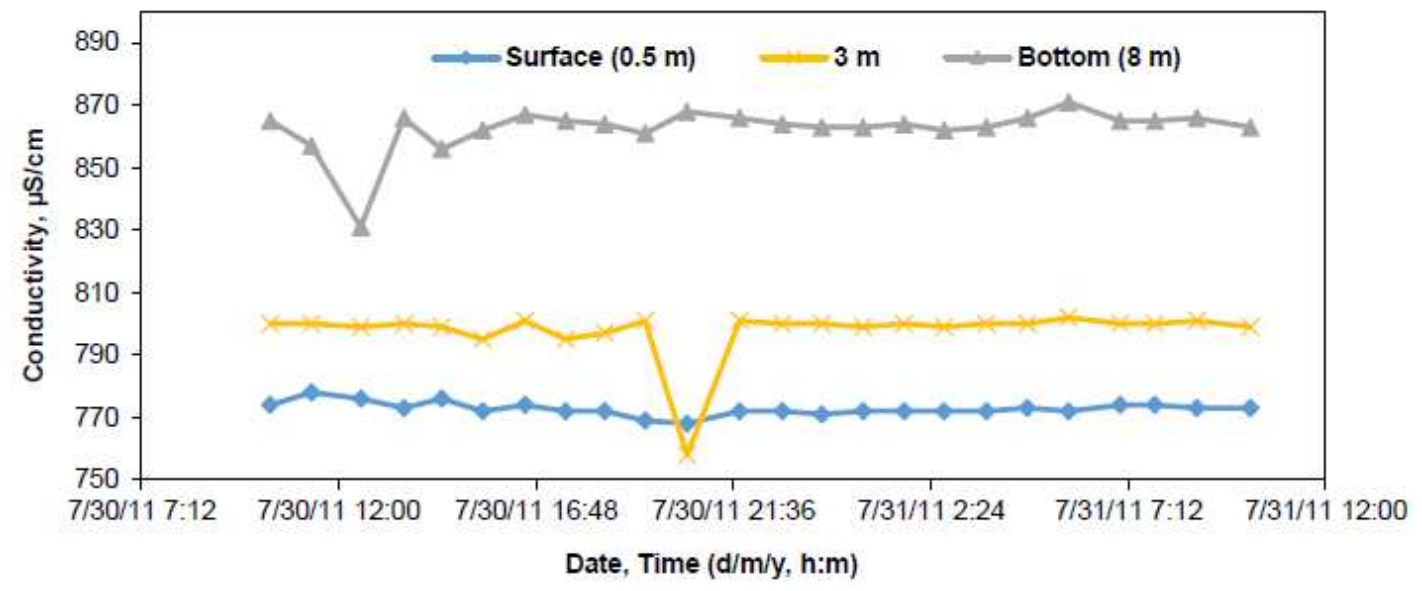

Fig. 7. Diurnal conductivity variation along the water column under non-aerated conditions at Site A

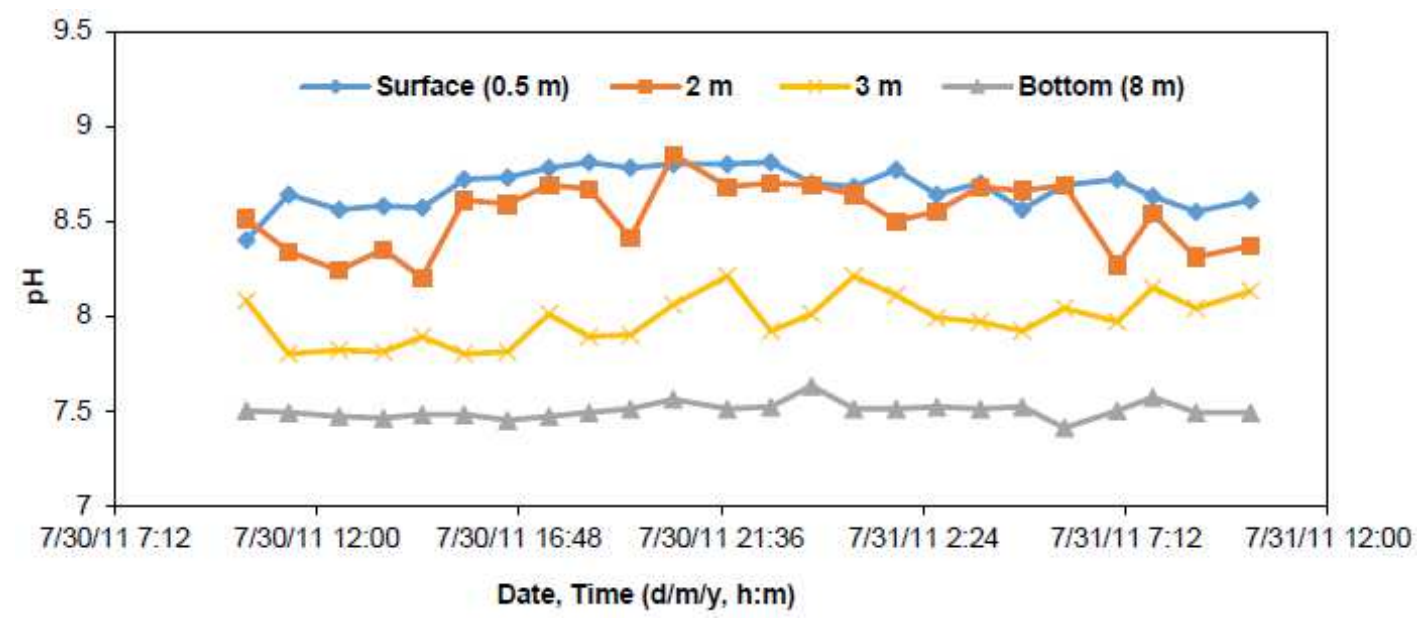

Fig. 8. Diurnal $\mathrm{pH}$ variation along the water column under non-aerated conditions at Site A 

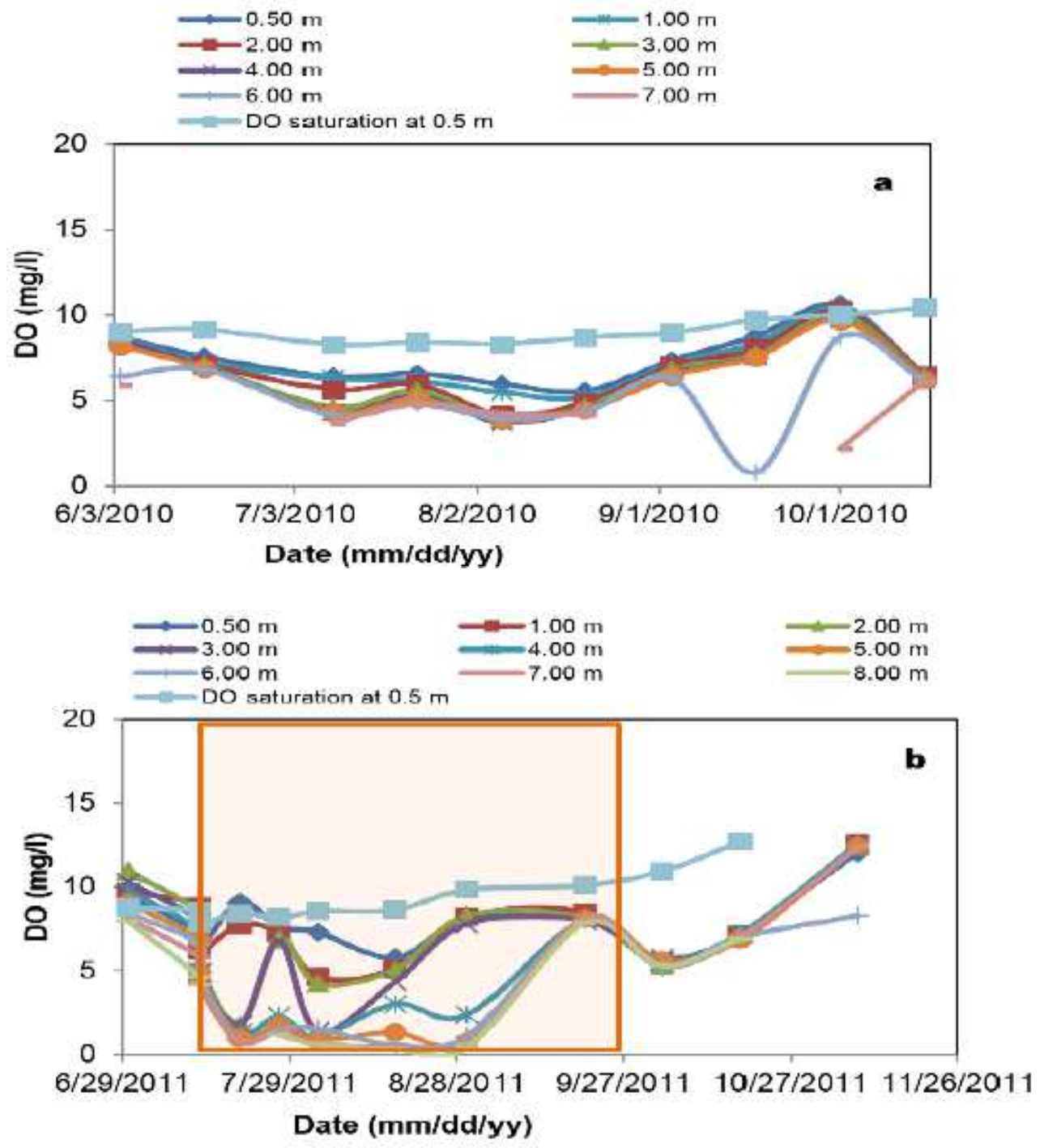

Date $(\mathrm{mm} / \mathrm{dd} / \mathbf{y y})$

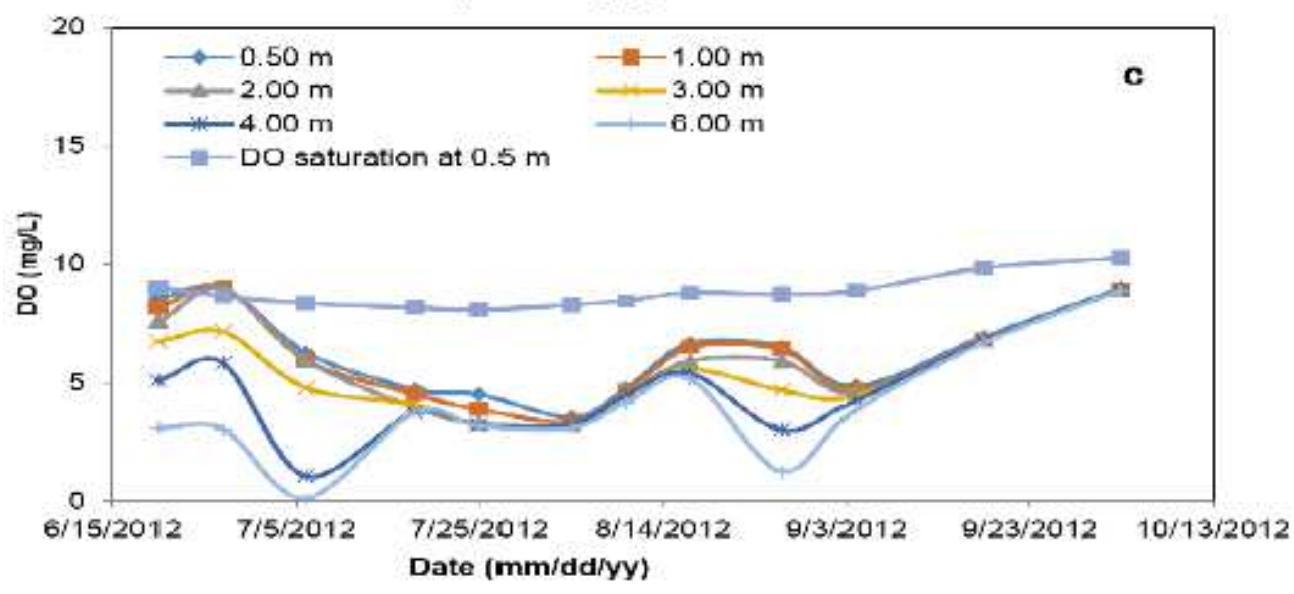

Fig. 9. Temporal and vertical variations of DO and DO saturation at Site A in (a) 2010 (b) 2011 and (c) 2012. The period without aeration indicated by shading 

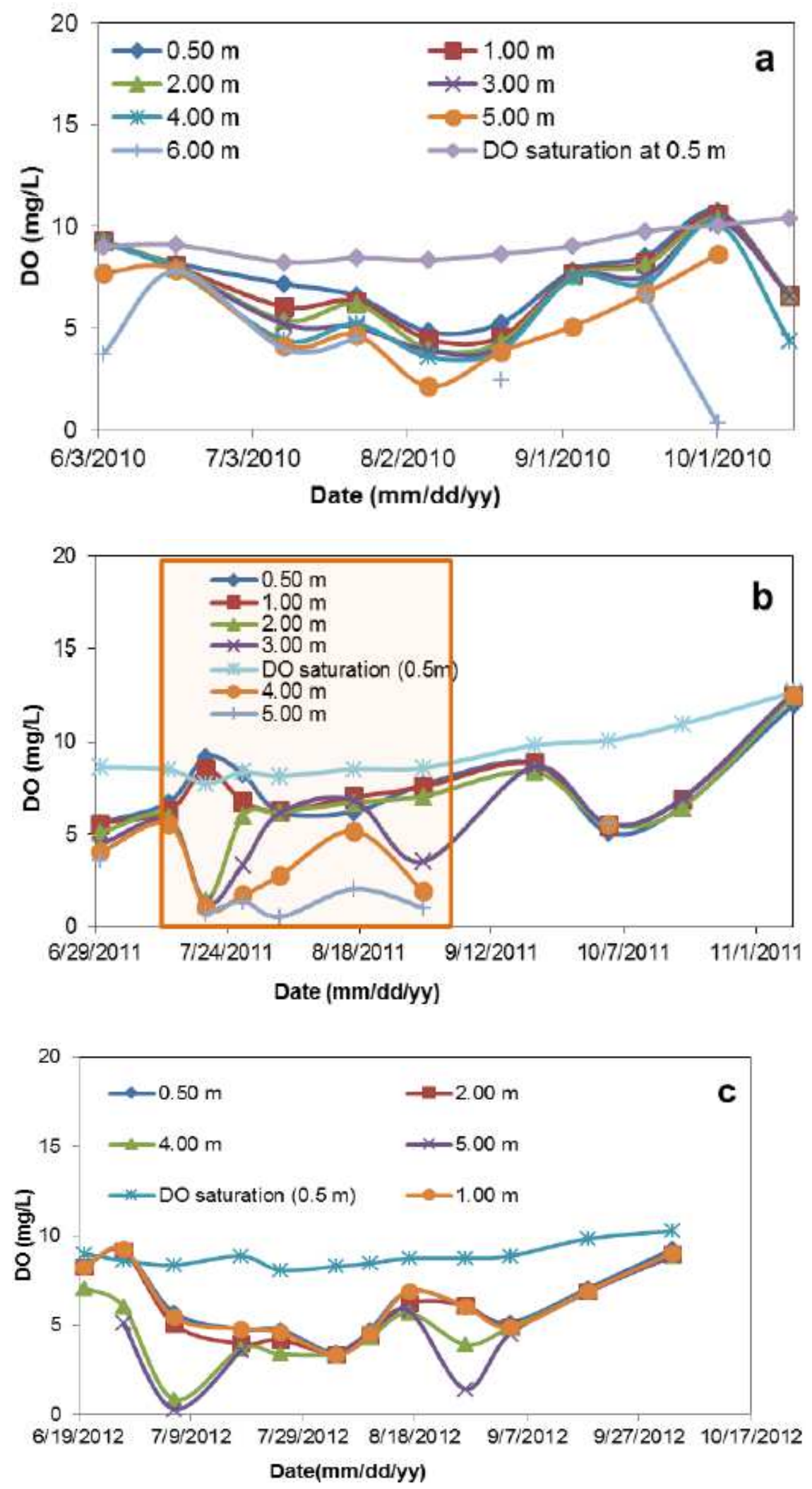

Fig. 10. Temporal and vertical variations of DO and DO saturation at Site B in (a) 2010 (b) 2011 and (c) 2012. The period without aeration indicated by shading 


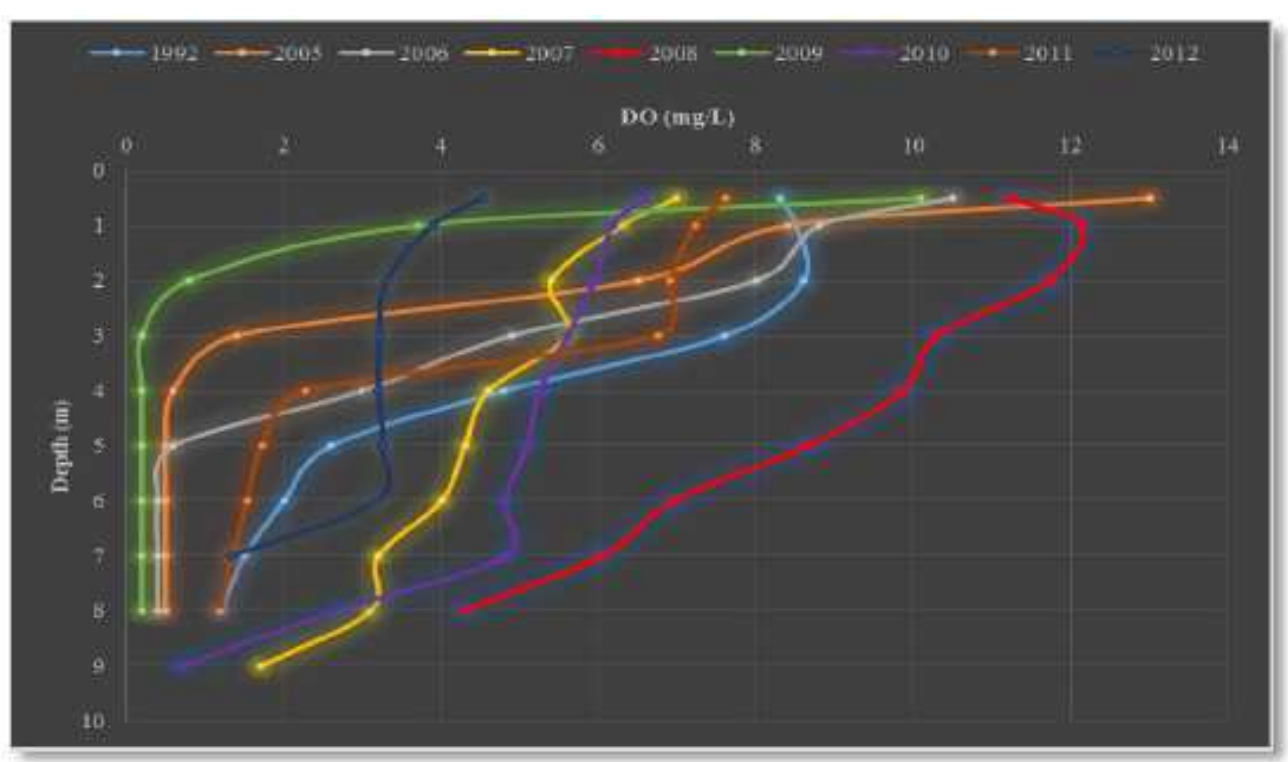

Fig. 11. Long term DO variation during pre-aerated (1992-2005) versus aerated (2006-2012) conditions at the deepest location, site A (Data source: NDG\&F)
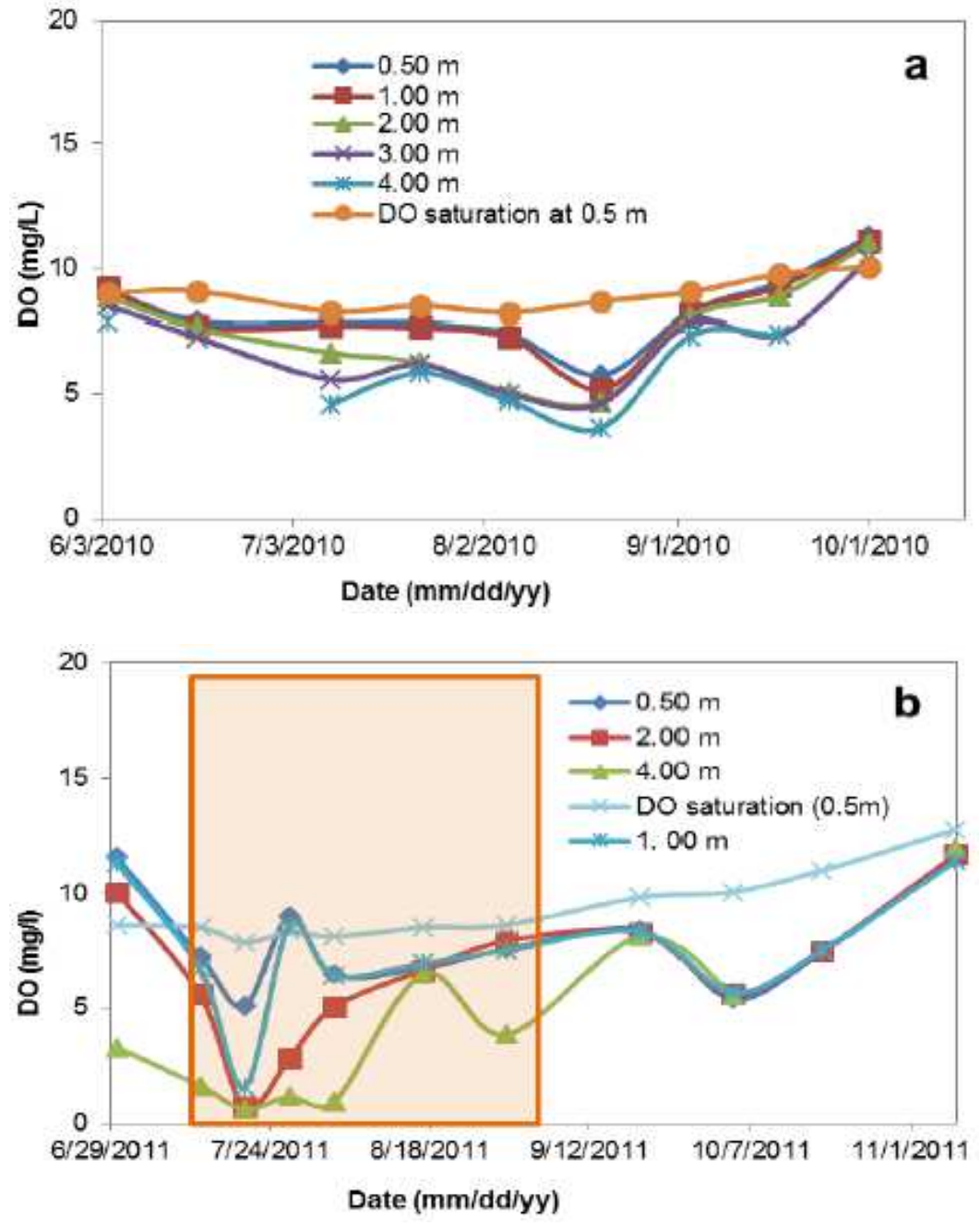


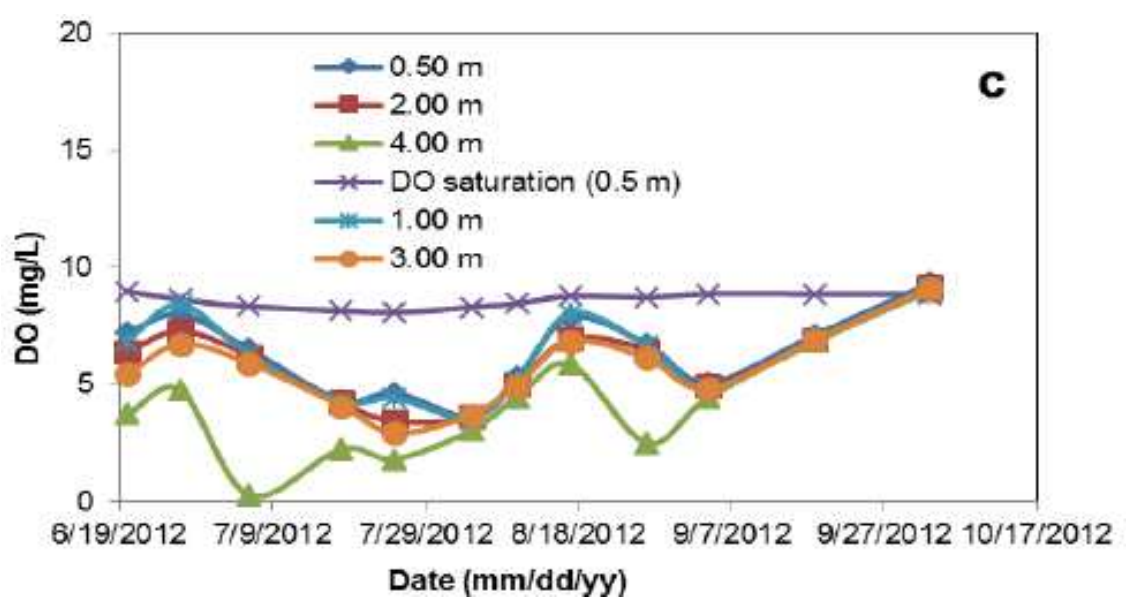

Fig. 12. Temporal and vertical variations of DO and DO saturation at Site C in (a) 2010 (b) 2011 and (c) 2012. The period without aeration indicated by shading
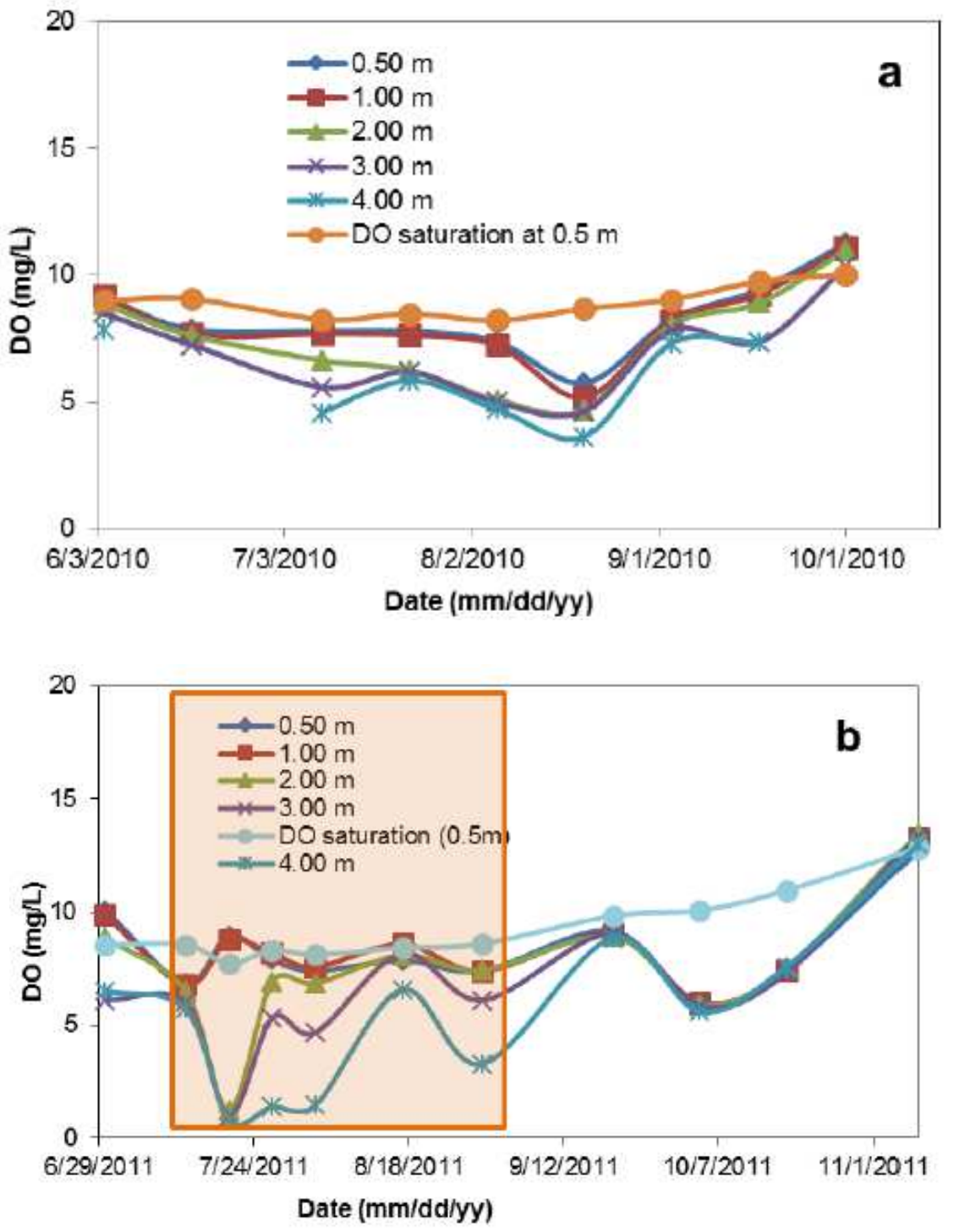


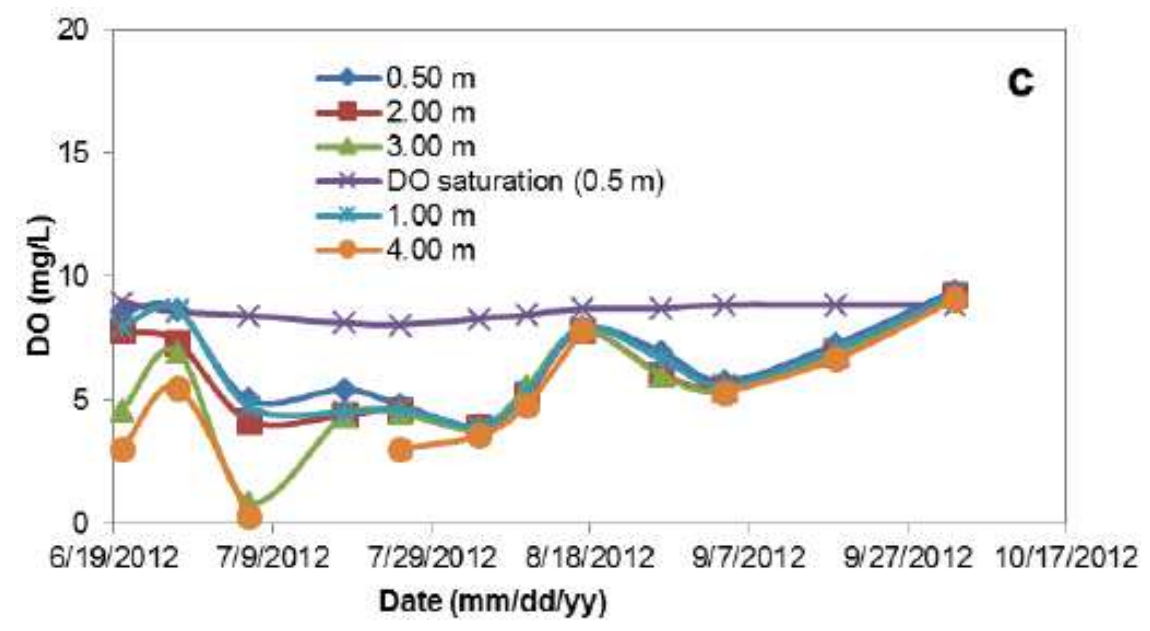

Fig. 13. Temporal and vertical variations of DO and DO saturation at Site D in (a) 2010 (b) 2011 and (c) 2012. The period without aeration indicated by shading
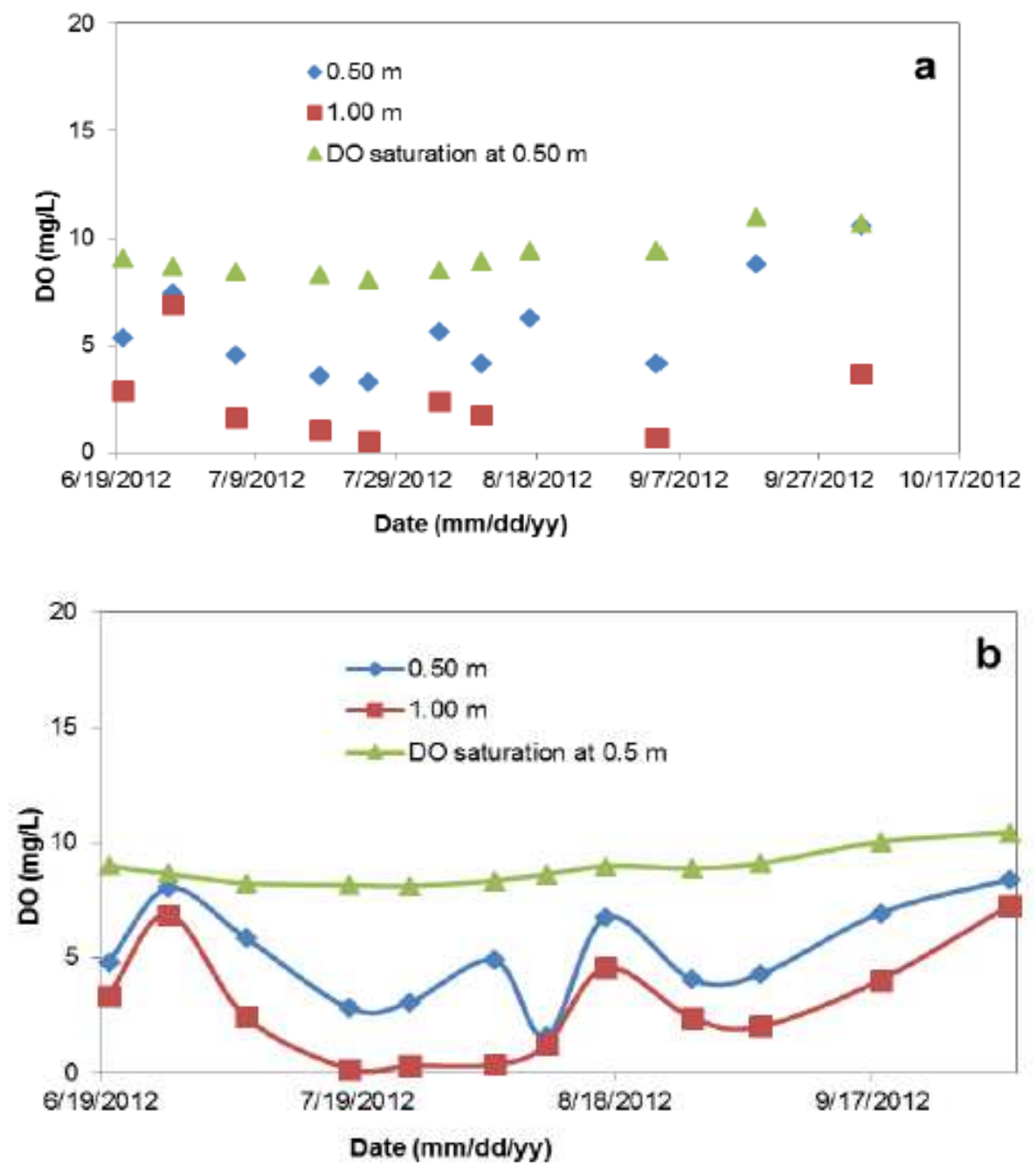

Fig. 14. Temporal and vertical variations of DO and DO saturation at (a) Site G and (b) Site H in 2012 


\section{Vertical and Spatial Distributions of DO and DO Saturation}

Figure 9-14 show spatial, temporal and vertical distributions of DO concentration and DO saturation at a deep portion (sites A-B), a shallow portion (sites C-D) and the shallowest areas/dead areas (sites G and $\mathrm{H})$ of the reservoir during the study period. The DO concentration in the surface layer of the deep portion of the reservoir was increased by the existing destratification system (Fig. 9a and 10a). In contrast, near-bottom layers exhibited lower DO than the daily minimum DO concentration of $5 \mathrm{mg} \mathrm{L}^{-1}$ under both aerated and non-aerated conditions (Fig. 9b, 9c and $10 \mathrm{~b}, 10 \mathrm{c})$. The comparison of DO concentration in the pre-aerated conditions (1992-2005) and aerated conditions (2006-2012; except 2009 and 2011) in summer at the deepest location reveals that the aeration increased DO concentration within the impoundment (Fig. 11). However, even with aeration, the DO concentration gradient at all the depths was observed during the study period. The DO concentration during the pre-aerated period was less than $5 \mathrm{mg} \mathrm{L}^{-1}$, which is the daily minimum DO concentration at all levels except at $1 \mathrm{~m}$ depth.

Compared to DO variations along the water column in a deep portions of the reservoir, the DO at shallow areas (sites C and D) exhibited increased DO concentration in near-bottom waters due to the wind mixing (Fig. 12a, 12b and 13a, 13b). Sites G and H are the shallowest areas (the maximum depth is $1.5 \mathrm{~m}$ ) and exposed to frequent sediment-water interactions and dominated by Coontail, Cattail, Duckweed and Milfoils (Fig. 14a and 14b). These sites are far from the aeration system and located in the inlet and dead area of the impoundment. The DO concentration in the surface layer at both locations dropped to less than the recommended value while aeration was in operation in 2012 (Fig. 14a and 14b). During the nonaerated period, the top most layer separated from the undisturbed hypolimnion; therefore, DO production occurred only in the surface layer due to algal photosynthesis and high DO consumption occurred in near-bottom layers. Among four sampling locations in the non-aerated period, a prolonged period of low DO was observed at site $\mathrm{A}$, which is the deepest location of the HMDI.

As shown in Fig. 9 to 14, DO saturation was calculated using the water temperature relevant to each sampling depth at each of six locations during the sampling period. The DO concentration decreased gradually from June to July at all sampling depths due to increasing water temperature; however, at the end of August when water temperature was decreasing, which increases the solubility of DO. The DO saturation followed the same trend as DO and the water column was undersaturated throughout the sampling period until by the end of October (Fig. 9-14). The DO concentration in the surface water column was closer to the saturation line compared to the near- bottom layers at all sampling locations.

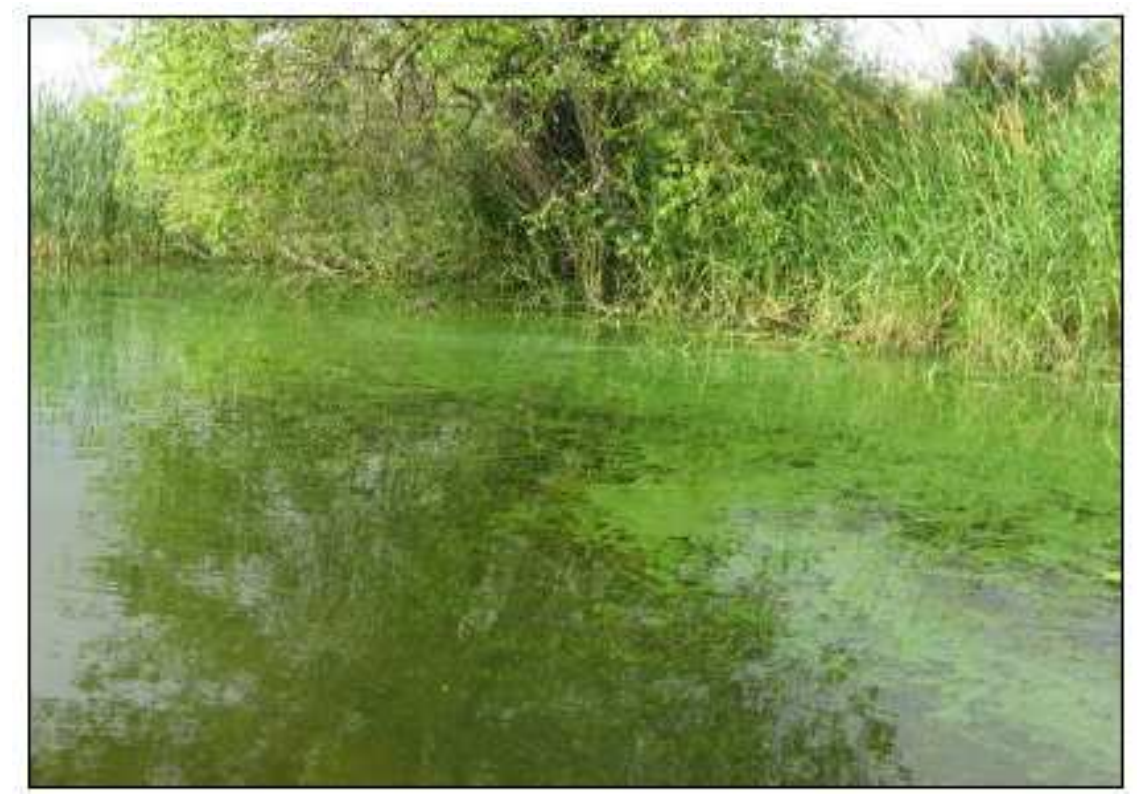

Fig. 15. Algal blooms during eutrophic conditions at HMDI. (Photo by Anusha Balangoda) 


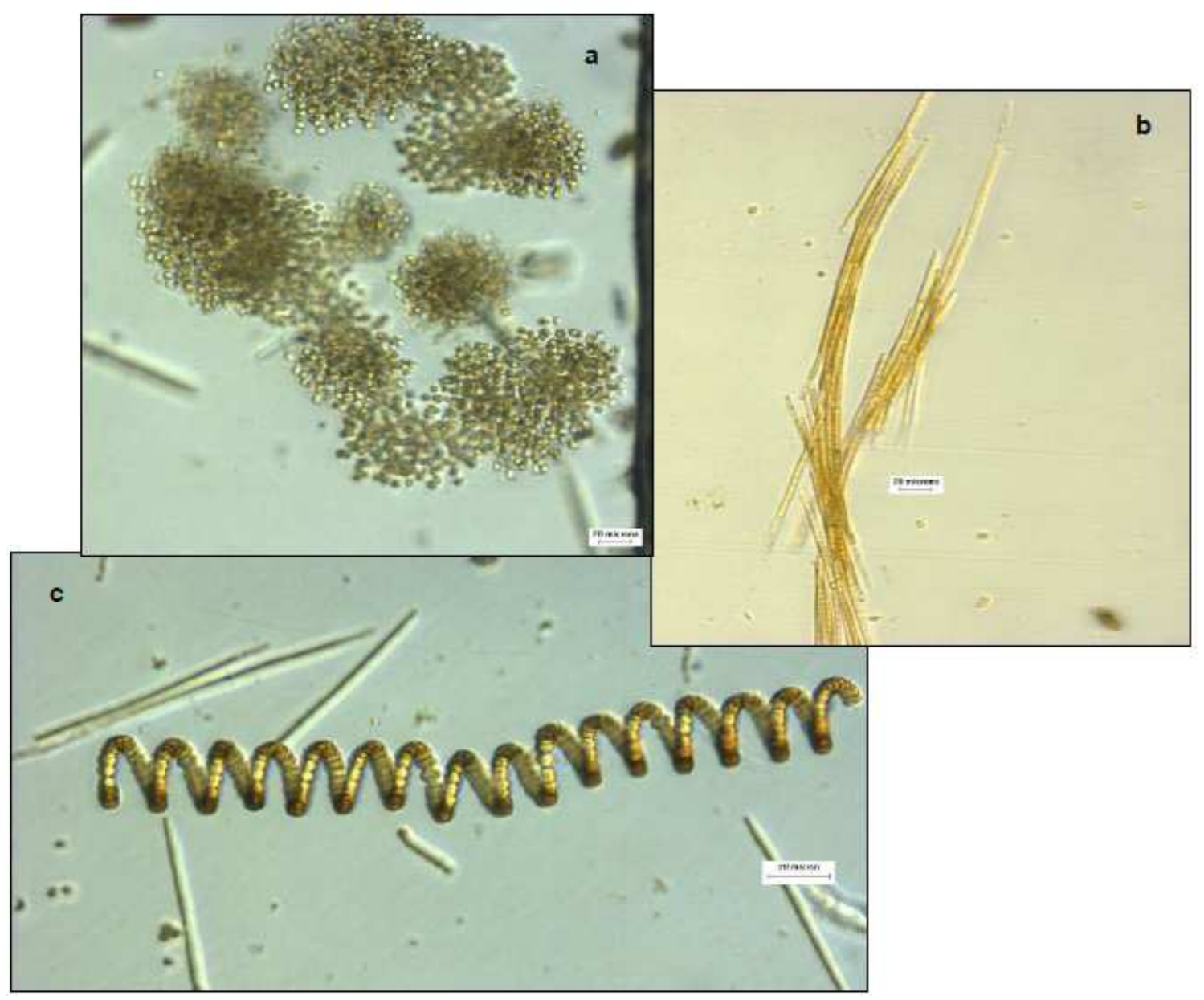

Fig. 16. Dominated cyanobacteria species at HMDI under an inverted microscope (viewed at $400 \times$ and scale is 20 microns) (a) Microcystis sp. (b) Aphanizomenon sp. (3) Anabaena sp. (Images by Anusha Balangoda)

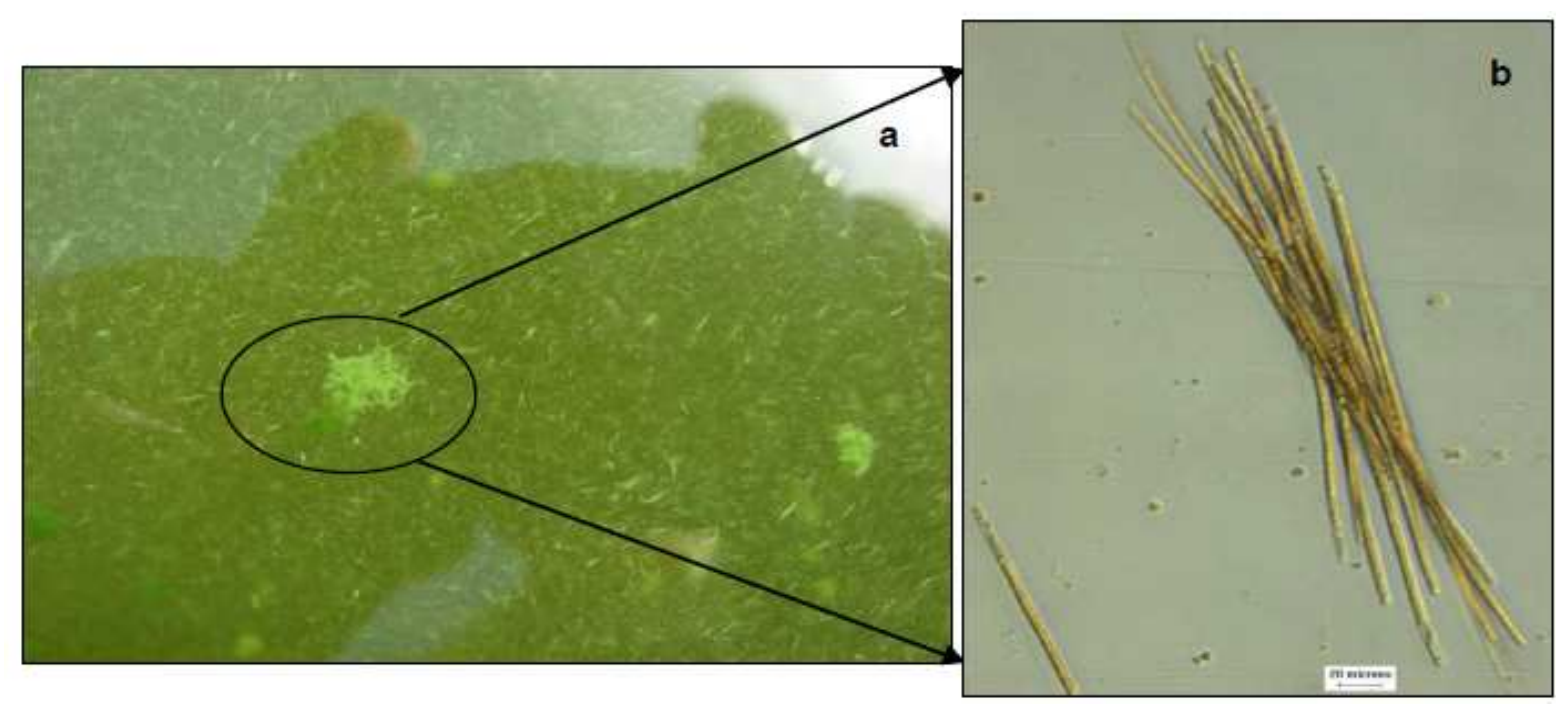

Fig. 17. (a) A closer view of algal bloom clumps at HMDI under non-aerated conditions and (b) Aphanizomenon sp. under inverted microscope (viewed at $400 \times$ and scale is 20 micron) (Photos by Anusha Balangoda) 


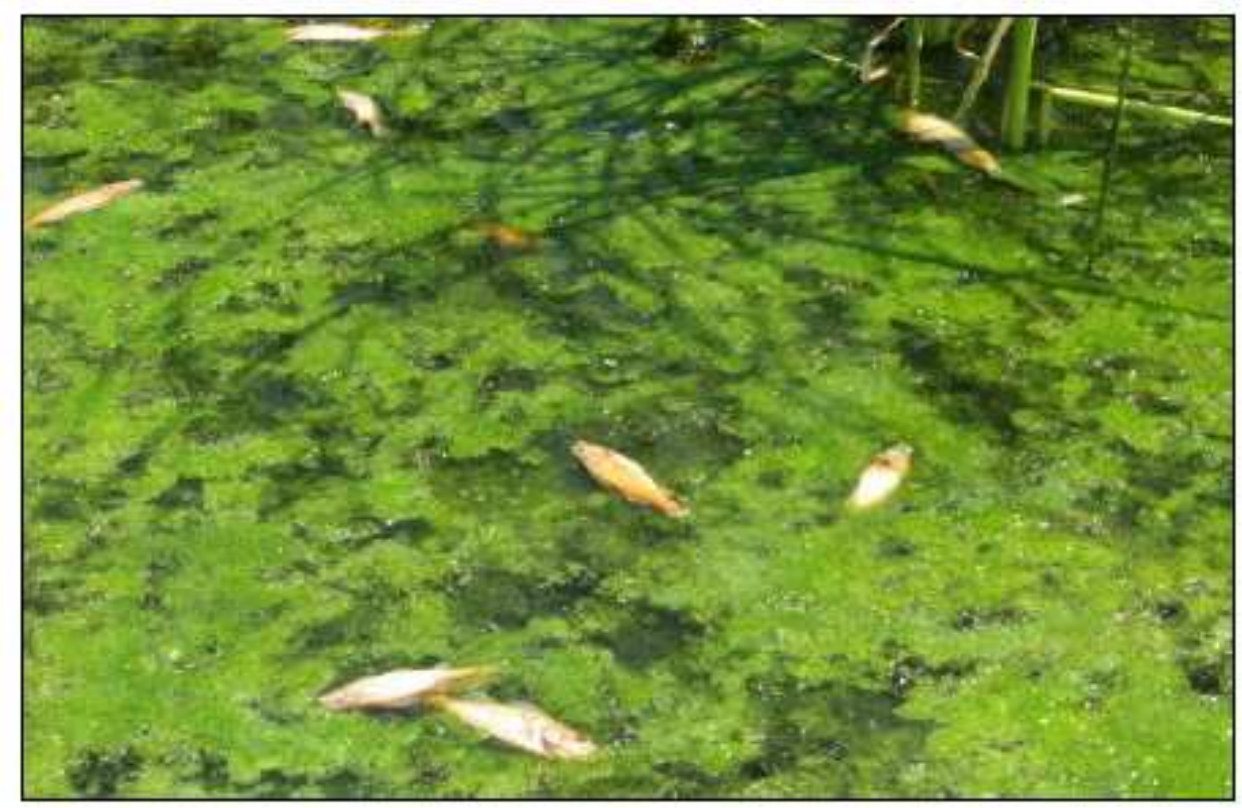

Fig. 18. Fish kill due to lack of oxygen at HMDI (Photo by Anusha Balangoda)

\section{Consequences of Eutrophication}

The most conspicuous effect of cultural eutrophication was excessive algal growth observed at HMDI under non-aerated conditions (stratified conditions) (Fig. 15). Total algal biomass (as represented by chlorophyll a concentration) was peaked $\left(94 \mu \mathrm{g} \mathrm{L}^{-1}\right)$ at the surface and Secchi depth levels at HMDI during bloom conditions (result are not shown). Algal biomass changed with the duration of thermal stratification (Balangoda et al., 2015). Turbidity also reached to its peak value (15 NTU) and resulted in a corresponding decrease in water clarity (result are not shown). The cyanobacterial bloom was observed at HMDI during the warm summer and under non-aerated conditions (low flushing and water column stability conditions). Based on the HMDI water quality outbreaks of cyanobacteria bloom was dominated by an assemblage of non-N2 fixing cyanobacteria (Microcyctis) and N2- fixing cyanobacteria (Aphanizomenon and Anabaena) during stratification (Fig. 16). The dense algal clusters were identified under the inverted microscope as filamentous nitrogen-fixing Aphanizomenon sp. (Fig. 17).

Fish kills were also observed in month of July under algal bloom conditions in the shallowest areas (sites $G$ and $\mathrm{H}$ ) which are not deep enough to stratify during the warm summer (Fig. 18). These sites are located far away from the aeration system and the dissolved oxygen concentration was dropped to less than $2 \mathrm{mg}$ $\mathrm{L}^{-1}$ (hypoxic conditions) at $1 \mathrm{~m}$ from the surface water column during day time (Fig. 14). The $24 \mathrm{~h}$ DO variations indicated that on warm summer nights during algal blooms, hypoxic conditions are possible and fish die-off can occur. Massive live and dead algal and plant biomass were observed in the shallow areas of the HMDI and accelerated organic matter decaying resulted in a rotten smell and black water in the shallow areas of the HMDI (Fig. 18).

\section{Discussion and Conclusion}

The purpose of the artificial aeration system at the HMDI (Heinrich Martin Dam Impoundment) was to improve the near-bottom water DO concentration in the entire impoundment to avoid summer fish kills and cyanobacterial blooms. However, the existing air diffusion system wasn't able to achieve through delivering compressed air above the bottom of the deepest portion of the impoundment. The HMDI air compressor was on operation for 5-6 months per year in early summer prior to lake stratification and then disconnected during late fall and winter months (November-April). The existing aeration system improved DO concentration in the deeper portion of the impoundment; however, the air diffusion was unable to improve the DO concentration in the shallowest areas (sites $\mathrm{G}$ and $\mathrm{H}$ ), which are located in the far from the aeration system. Artificial aeration was not able to equalize the distribution of DO across the entire impoundment.

Spatial variations of DO showed that the HMDI has partially destratified. This inadequacy is due to the fact that the aeration system was located near the deep 
portion of the impoundment; therefore, the areas that are far from the system are less affected by the aeration such as, the shallowest locations. The deeper portion of the impoundment remained stratified during warm summer until the cooler fall air temperatures allowed the water layers to become isothermal and mix again. In the shallowest areas, however, the sediment surface sufficiently oxidized because of wind mixing. The DO concentrations at the shallowest locations indicated that the only one aeration system was incapable of aerating the entire impoundment.

A previous study (Overmoe, 2008) showed higher Biochemical Oxygen Demand (BOD) and Chemical Oxygen Demand (COD) in the bottom layer of the deep location of the same one, which indicated a high concentration of organic matter in near-bottom layers. In addition, this study showed that the percent of volatile organic matter content in the bottom sediment of the HMDI was between 14 and 19\%, which was higher than the organic matter content in fertile agricultural soils, which is between 3 and $6 \%$. Furthermore, results indicated that due to the high organic matter content in near-bottom layers, artificial aeration temporally increases DO concentration in the water column. Aeration might redistributes organic matter derived from organic matter decomposition in the bottom sediments and along the water column by resuspension making it available for algal growth in the hypolimnion (James et al., 1990). Cooke et al., (2005) also reported that inadequate aeration caused incomplete destratification that was, in turn, responsible for undesirable water quality results.

Other studies have shown cyanobacteria bloom was potential under relatively high water temperatures during summer (Paerl and Paul, 2012). Carey et al., (2012) also observed that calm conditions and thermal stratification that coincide with high temperatures can cause result in the buoyancy-regulating cyanobacteria like Aphanizomenon (Fig. 17). An additional threat posed by cyanobacteria was found to come from Anabaena and Microcystis, which are toxigenic cyanobacteria (Watson et al., 2016). Cyanobacteria growth is promoted by changes of internal and external nutrient loadings and increased temperature (Conroy et al., 2005; McCormick and Fahnenstiel, 1999). In addition, studies have reported that climate change is predicted to expedite to temperatures and stratification patterns beneficial for cyanobacterial growth (Paerl and Huisman, 2008; 2009; Wagner and Adrian, 2009) and contribute to hypoxia (Lynch et al., 2010).

This study reveals through $24 \mathrm{~h}$ monitoring that excessive algal and weed growth cause major impacts on diurnal DO variation along the water column during warm summers. The existing aeration system (artificial destratification) was shown to be only a temporary solution to improve the DO concentration in the water column and artificial destratification further influenced organic matter resuspension, which lead to high sediment DO consumption. Furthermore, results indicated that the shallowest areas are highly vulnerable to anoxic conditions and fish kills during warm summer due to wind driven sediment-water interactions and rich organic sediments. This study provides evidence that the existing aeration system (artificial destratification system) was only partially effective in terms of improving the DO concentration in entire impoundments. Moreover, findings of this study will help to make necessary adjustments to existing aeration systems to improve DO concentration in the entire impoundment. Therefore, future work should focus on another possible aeration systems such as, hypolimnetic oxygenation that limits nutrient resuspension from the sediment.

\section{Acknowledgment}

This research was financially supported by a grant from the North Dakota Water Resources Research Institute (2010, 2011 and 2012 fellowships). In addition, North Dakota State University's Civil and Environmental Engineering laboratory provided facilities for chemical analyses and North Dakota Game and Fish Department provided a boat for water sample collection. Special thanks are given to my advisers Shafiqur Rahman and G. Padmanabhan for their valuable guidance and advice. I also thank Malcolm Butler of North Dakota State University's Department of Biological Sciences for providing some equipment for field sampling. I thank Wei Lin and Veselina Volkov for their assistance in field sampling and sample analyses. I especially thank Enricco Sassi for reviewing the draft manuscript.

\section{Ethics}

This manuscript has neither been published, nor under consideration for publication or in press elsewhere concurrently.

\section{References}

Balangoda, A., 2016. Artificial destratification effects on nitrogen and phosphorus dynamics in a eutrophic impoundment in the Northern Great Plains. Environ. Monitor. Assess. 188: 1-19.

DOI: $10.1007 / \mathrm{s} 10661-016-5444-7$

Balangoda, A., G. Padmanabhan and S. Rahman, 2015. Effects of intermittent artificial circulation in summer months on chlorophyll $a$ concentration in a small eutrophic impoundment. Am. J. Environ. Sci., 11: 380-391.

DOI: 10.3844 /ajessp.2015.380.391 
Beutel, M.W. and A.J. Horne, 1999. A review of the effects of hypolimnetic oxygenation on lake and reservoir water quality. Lake Reservoir Manage., 15: 285-297. DOI: 10.1080/07438149909354124

Bridgeman, T.B., D.W. Schloesser and A.E. Krause, 2006. Recruitment of Hexagenia mayfly nymphs in western Lake Erie linked to environmental variability. Ecol. Applic., 16: 601-611.

DOI:

$10.1890 / 1051-$ 0761(2006)016[0601:ROHMNI]2.0.CO;2

Carey, C.C., H.A. Ewing, K.L. Cottingham, K.C. Weathers and R.Q. Thomas et al., 2012. Occurrence and toxicity of the cyanobacterium Gloeotrichia echinulata in low-nutrient lakes in the northeastern United States. Aquatic Ecol., 46: 395-409.

DOI: $10.1007 / \mathrm{s} 10452-012-9409-9$

Christophoridis, C. and K. Fytianos, 2006. Conditions affecting the release of phosphorus from surface lake sediments. J. Environ. Quality, 35: 1181-1192. DOI: $10.2134 /$ jeq2005.0213

Conroy, J. D., W.J. Edwards, R.A. Pontius, D.D. Kane and H. Zhang et al., 2005. Soluble nitrogen and phosphorus excretion of exotic freshwater mussels (Dreissena spp.): potential impacts for nutrient remineralisation in western Lake Erie. Freshwater Biol., 50: 1146-1162.

DOI: $10.1111 / \mathrm{j} .1365-2427.2005 .01392 . x$

Cooke, G.D., E.B. Welch, S.A. Peterson and S.A. Nichols, 2005. Restoration and Management of Lakes and Reservoirs. 3rd Ed., Taylor and Francis, New York, ISBN-10: 1566706254, pp: 616.

Eby, L.A. and L.B. Crowder, 2002. Hypoxia-based habitat compression in the Neuse River estuary: Context-dependent shifts in behavioral avoidance thresholds. Canad. J. Fisheries Aquatic Sci., 59: 952-965. DOI: 10.1139/f02-067

Gächter, R. and B. Muller, 2003. Why the phosphorus retention of lakes does not necessarily depend on the oxygen supply to their sediment surface. Limnol. Oceanography, 48: 929-933.

DOI: $10.4319 / 10.2003 .48 .2 .0929$

Gächter, R. and B. Wehli, 1998. Ten years of artificial mixing and oxygenation: No effect on the internal phosphorus loading of two eutrophic lakes. Environ. Sci. Technol., 32: 3659-3665.

DOI: $10.1021 /$ es9804181

Gächter, R., 1987. Lake restoration: Why oxygenation and artificial mixing cannot substitute for a decrease in the external phosphorus loading. Swiss J. Hydrol., 49: 170-185. DOI: 10.1007/BF02538501

Hupfer, M. and J. Lewandowski, 2008. Oxygen controls the phosphorus release from lake sediments - a longlasting paradigm in limnology. Int. Rev. Hydrobiol., 93: 415-432. DOI: 10.1002/iroh.200711054
James, W.F., R.H. Kennedy and R.F. Gaugush, 1990. Effects of large-scale metalimnetic migration events on phosphorus dynamics in a north-temperate reservoir. Aquatic Sci., 47: 156-162.

DOI: $10.1139 / \mathrm{f90}-016$

Ludsin, S.A., X.S. Zhang, S.B. Brandt, M.R. Roman and W.C. Boicourt et al., 2009. Hypoxia-avoidance by planktivorous fish in Chesapeake Bay: Implications for food web interactions and fish recruitment. J. Exp. Marine Biol. Ecol., 381: 121-131.

DOI: 10.1016/j.jembe.2009.07.016

Lynch, A.J., W.W. Taylor and K.D. Smith, 2010. The influence of changing climate on the ecology and management of selected Laurentian Great Lakes fisheries. J. Fish Biol., 77: 1964-1982. DOI: $10.1111 /$ j.1095-8649.2010.02759.x

McCormick, M.J. and G.L. Fahnenstiel, 1999. Recent climatic trends in nearshore water temperatures in the St. Lawrence Great Lakes. Limnol. Oceanography, 44: 530-540. DOI: 10.4319/lo.1999.44.3.0530

Michalak, A.M., E.J. Anderson, D. Beletsky, S. Boland and N.S. Bosch et al., 2013. Record-setting algal bloom in Lake Erie caused by agricultural and meteorological trends consistent with expected future conditions. Proc. Nat. Acad. Sci., 110: 6448-6452. DOI: 10.1073/pnas. 1216006110

NDDoH, 2010. North Dakota 2010 integrated section 305(b) water quality assessment report and section 303(d) list of waters needing total maximum daily loads. North Dakota Department of Health, Division of Water Quality.

Overmoe, K.A., 2008. Influence of artificial aeration on water quality at Heinrich-Martin Impoundment, North Dakota. Thesis, North Dakota State University.

Paerl, H.W. and J. Huisman, 2008. Blooms like it hot. Science, 320: 57-58. DOI: 10.1126/science. 1155398

Paerl, H.W. and J. Huisman, 2009. Climate change: A catalyst for global expansion of harmful cyanobacterial blooms. Environ. Microbiol. Rep., 1: 27-37. DOI: $10.1111 / \mathrm{j} .1758-2229.2008 .00004 . x$

Paerl, H.W., N.S. Hall and E.S. Calandrino, 2011. Controlling harmful cyanobacterial blooms in a world experiencing anthropogenic and climaticinduced change. Sci. Total Environ., 409: 1739-1745. DOI: 10.1016/j.scitotenv.2011.02.001

Paerl, H.W., V.J. Paul, 2012. Climate change: Links to global expansion of harmful cyanobacteria. Water Res., 46: 1349-1363.

DOI: $10.1016 /$ j.watres.2011.08.002

Rabalais, N.N., R.J. Díaz, L.A. Levin, R.E. Turner and D. Gilbert et al., 2010. Dynamics and distribution of natural and human-caused hypoxia. Biogeosciences, 7: 585-619. DOI: $10.5194 /$ bg-7-585-2010 
Rao, Y.R., T. Howell, S.B. Watson and S. Abernethy, 2014. On hypoxia and fish kills along the north shore of Lake Erie. J. Great Lakes Res., 40: 187-191. DOI: 10.1016/j.jglr.2013.11.007

Singleton, V.L. and J.C. Little, 2006. Designing hypolimnetic aeration and oxygenation systems- a review. Environ. Sci. Technol., 40:7512-7520. DOI: $10.1021 / \mathrm{es} 060069 \mathrm{~s}$

Steffen, M.M., B.S. Belisle, S.B. Watson, G.L. Boyer and S.W. Wilhelm, 2014. Status, causes and controls of cyanobacterial blooms in Lake Erie. J. Great Lakes Res., 40: 215-225.

DOI: $10.1016 /$ j.jglr.2013.12.012

Stewart, T.W. and R.L. Lowe, 2008. Benthic algae of Lake Erie (1865-2006): A review of assemblage composition, ecology and causes and consequences of changing abundance. Ohio J. Sci., 108: 82-94.
Wagner, C. and R. Adrian, 2009. Cyanobacteria dominance: Quantifying the effects of climate change. Limnol. Oceanography, 54: 2460-2468. DOI: 10.4319/1o.2009.54.6_part_2.2460

Watson, S.B., C. Miller, G. Arhonditsis, G.L. Boyer and W. Carmichael et al., 2016. The re-eutrophication of Lake Erie: Harmful algal blooms and hypoxia. Harmful Algae, 56: 44-66. DOI: $10.1016 /$ j.hal.2016.04.010

Wax, P., A. McDonald and M. Ell, 2008. North Dakota Lake Water Quality Assessment Reports. North Dakota Department of Health: Division of Water Quality.

Zhou, Y, D.R. Obenour, D. Scavia, T.H. Johengen and A.M. Michalak, 2013. Spatial and temporal trends in Lake Erie hypoxia, 1987-2007. Environ. Sci. Technol., 47: 899-905. DOI: 10.1021/es303401b 